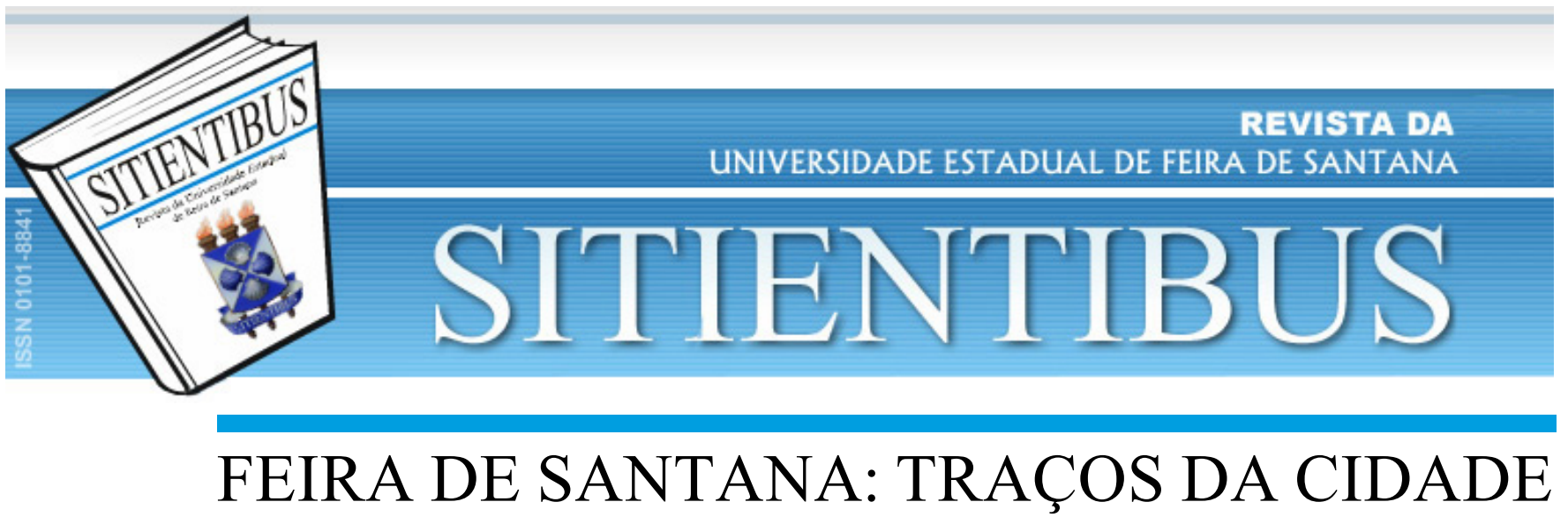

ARTIGO

\title{
PARTICIPAÇÃO SOCIAL NO ÂMBITO DA POLÍTICA DE HABITAÇÃO NO MUNICÍPIO DE FEIRA DE SANTANA-BA
}

\section{SOCIAL PARTICIPATION IN THE FRAMEWORK OF THE HOUSING POLICY IN THE MUNICIPALITY OF FEIRA DE SANTANA-BA}

\section{LIDIANE RIOS DE OLIVEIRA}

Assistente Social/FAN. Especialista em Gestão Pública/UNIVASF. Mestra em Planejamento Territorial/UEFS. Email: lidianerios86@gmail.com

\section{RESUMO}

Este artigo manifesta uma discussão sobre a participação social como processo político capaz de inserir as camadas empobrecidas da sociedade nas esferas de tomadas de decisões políticas e, assim, assegurar direitos. A compreensão da participação social, neste texto, está atrelada à política de habitação no município de Feira de Santana - Ba, com ênfase no Programa Minha Casa Minha Vida (PMCMV). Para alcançar a proposta, apresentou-se uma análise teórica sobre participação social e, logo após, um estudo documental, de caráter local, baseado nos seguintes documentos: o Plano Local de Habitação de Interesse Social (PLHIS) do município de Feira de Santana; a Lei no 3522/2015, que criou o Conselho da Cidade de Feira de Santana; e o Relatório da 5a Conferência da Cidade de Feira de Santana. No quesito legalização e normatização, a participação se fortaleceu intensamente nas últimas décadas. No entanto, em Feira de Santana, foi possível observar que as estratégias de aplicação dos mecanismos de participação precisam ser revisadas e trabalhadas nas comunidades com um envolvimento maior. A gestão do município, além de sancionar leis e decretos, necessita instituir canais que de fato desenvolvam o controle social e deve atentar-se para a divulgação desses canais e para a acessibilidade dos mesmos.

Palavras-chave: Participação social. Política de habitação. Poder público.

\section{ABSTRACT}

This article expresses a discussion about social participation as a political process capable of inserting the impoverished layers of society in the spheres of political decision making and, thus, securing rights. The understanding of social participation in this work is linked to the housing policy in the municipality of Feira de Santana - Ba, with an emphasis on the My House My Life Program (PMCMV). In order to reach the proposal, a theoretical analysis was presented on social participation and soon after a documentary study, of local character, based on the following documents: the Local Plan of Housing of Social Interest (PLHIS) of the municipality of Feira de Santana; Law No. 3522/2015, which created the City Council of Feira de Santana; and the Report of the 5th Conference of the City of Feira de Santana. In terms of legalization and standardization, participation has intensified in recent decades. However, in Feira de Santana, it was possible to observe that the strategies for applying participation mechanisms need to be reviewed and worked on in communities with greater involvement. The management of the municipality, in addition to sanctioning laws and decrees, needs to establish channels that in fact develop social control and should be attentive to the disclosure of these channels and their accessibility.

Keywords: Social participation. Housing policy. Public power. 


\section{INTRODUÇÃO}

A participação social é uma estratégia de decisão política que possibilita aos cidadãos a oportunidade de terem os seus direitos garantidos, por meio da inserção dos mesmos nas esferas de controle social. Nesse sentido, o propósito deste texto é apresentar uma reflexão sobre a participação, associada a política de habitação no município de Feira de Santana, com ênfase no Programa Minha Casa Minha Vida (PMCMV).

Em Feira de Santana, cidade localizada na Bahia, a uma distância de $108 \mathrm{~km}$ da capital, Salvador, está concentrado um número significativo de unidades habitacionais financiadas pelo PMCMV, totalizando quarenta e dois empreendimentos, segundo dados do Relatório Anual do Programa de Convivência Social e Cidadania (PCSC) do ano de 2014 ${ }^{1}$. Teoricamente, esse crescimento imobiliário contribuiu para a redução do déficit habitacional, pois, de acordo com informações da Prefeitura Municipal de Feira de Santana, já foram entregues 10.228 unidades residenciais (FEIRA DE SANTANA, 2015).

O município de Feira de Santana caracteriza-se como um espaço relevante para a presente análise, pois, apesar do crescimento no setor habitacional, decorrente do número de construções realizadas, ainda constitui-se de áreas desprovidas de infraestrutura, serviços e equipamentos públicos, que deveriam ser capazes de atender a todos os novos núcleos habitacionais. Nesse contexto, a participação social deve ser utilizada como um mecanismo de seguridade de direitos, que possibilite aos cidadãos o acesso aos serviços públicos básicos, garantindo-lhes a oportunidade de expressarem as necessidades comunitárias.

Este texto contempla a temática apresentada em duas etapas, além da parte introdutória e das considerações finais. A primeira trata da análise conceitual, baseada em uma revisão bibliográfica, sobre participação social; a segunda, apresenta um estudo documental, de caráter local, baseado nos seguintes documentos: o Plano Local de Habitação de Interesse Social (PLHIS) do município de Feira de Santana; a Lei no 3522/2015, que criou o Conselho da Cidade de Feira de Santana; e o Relatório da $5^{a}$ Conferência da Cidade de Feira de Santana.

\section{PARTICIPAÇÃO SOCIAL COMO PROCESSO POLÍTICO}

A participação social é um meio de inserção consciente, participativo e dinâmico de pessoas, grupos e/ ou organizações nos processos sociais, econômicos, políticos que refletem o interesse da coletividade nas comunidades em que o sujeito se insere. Apresenta como elemento significativo a consciência coletiva, pois a representatividade comunitária é um elemento de força, diferentemente da representação de apenas um indivíduo isolado.
A tomada de consciência do indivíduo no processo de participação está relacionada com a percepção de sua realidade concreta, sendo imprescindível "[...] analisar as condições reais e atuais da sua existência; exprimir seus verdadeiros interesses e criar formas de ação para a concretização desses interesses" (AMMANN, 2003, p. 139). Para tanto, a análise do espaço de vivência é um instrumento de extrema importância para a população, iniciando, assim, um processo de transformação que inclui a maneira de enxergar o local, fazer o levantamento das demandas sociais e colocar em prática ações que viabilizem uma melhor qualidade de vida.

A participação é uma estratégia que pode ser utilizada para a concretização dos direitos sociais - entendidos como o direito à saúde, educação, moradia, saneamento, dentre outros - e para o alcance dos objetivos do grupo, o que possibilita uma melhor qualidade de vida. Por essa razão, "[...] a participação social não representa um sujeito social específico, mas se constrói como modelo de relação/ideal, na relação sociedade/Estado" (GOHN, 2001, p. 58).

Para analisar a participação social nos empreendimentos do PMCMV é interessante adotar alguns argumentos de Souza, quando trata da distinção de dois tipos de luta na esfera do ativismo: "de bairro" e "a partir do bairro". A luta de bairro expressa à articulação de um grupo criticamente vulnerável, que pode ser facilmente cooptado e enfraquecido. Já a luta a partir do bairro retrata "[...] horizontes políticos mais amplos e a possibilidade (ou realidade) de articulação com outros ativismos e organizações" e que não se baseia apenas na satisfação de demandas imediatas (2006, p. 286).

Há algumas crenças difundidas na sociedade que dificultam a inclusão de novos atores sociais no processo de participação social na gestão pública. No que diz respeito à esfera da habitação, cita-se como exemplo a ideia de que as pessoas não estão "[...] preparadas para decidir qual a melhor solução habitacional e urbanística para a sua família e a sua área"; a sociedade não possui conhecimento suficiente para ser sujeito político das políticas públicas; e a "[...] sociedade dificulta a tomada de decisões, seja pela questão do tempo [...], seja pela questão de posicionamento crítico diante das propostas ou ausência delas por parte do Estado" (BRASIL, 2011, p. 24).

É necessário superar esses mitos e caminhar em direção ao desenvolvimento de uma organização comunitária proveniente da conquista consciente de uma nova postura. A população deve estar articulada e organizada, pois essa "[...] projeta, avalia e confronta sua força social com a dinâmica da realidade social" por meio da tomada de consciência em direção a tomada de decisão (SOUZA, 2008, p. 93).

Outra proposta é a formação de "[...] profissionais especializados em técnicas e estratégias de planejamento e rotinas de gestão dentro de uma mentalidade que não seja tecnocrática", meramente direcionada para manutenção da ordem vigente, do mesmo modo que se invista no envolvimento

${ }^{1}$ O PCSC é vinculado a Prefeitura Municipal de Feira de Santana e responsável pelo trabalho social executado nos residenciais do PMCMV no município. 
da "[...] sociedade civil, informando-a e capacitando-a para melhor poder participar" (SOUZA, 2006, p. 263-264). Com base no mesmo autor, é necessário manter uma desconfiança em relação ao Estado, no entanto, a cooptação, aniquilação ou não consolidação dos esforços empreendidos nem sempre representarão a anulação da sua influência.

Com efeito, para que uma comunidade se desenvolva é imprescindível que o sujeito participe ativamente, sendo capaz de refletir, questionar sua realidade e modificá-la, conforme ainda acrescenta Souza:

A participação, assim como o processo de conscientização, não se opera no vazio; supõe sempre um contexto de referência no qual, por sua vez, se encontra sempre um processo real de participação ou conscientização. Esse processo pode ser mais ou menos desenvolvido, não importa; o fato é que ele existe, e é a partir da realidade em que ele se encontra que se pode considerar as ações a serem desenvolvidas como conscientes, capazes de assumir um caráter educativo em função do processo de participação (2008, p. 90).

Acerca disso, esclarece-se que comunidade é um “[...] grupo permanente de pessoas que ocupa uma zona comum, desenvolve interação dentro e fora de seus papéis institucionais e possui um sentimento de identificação resultante dessa interação". Assim, envolve formas de relacionamento e realiza-se na união de vontades individuais (SILVA, 2003, p.15-16).

A participação social, quando pensada no âmbito das habitações de interesse social, é um desafio, uma vez que as famílias que ocupam essas moradias são oriundas de locais e realidades distintas, e precisam aprender a conviver e a estabelecer objetivos em comum. Assim, o sentimento de fazer parte de uma comunidade, com o reconhecimento das necessidades compartilhadas por todos, é imprescindível para que a participação social tenha êxito.

As conquistas dos movimentos sociais são exemplos de como a participação social no Brasil contribuiu para uma mudança estrutural na concepção das políticas públicas, pois foram estabelecidas parcerias entre Estado e sociedade civil na elaboração, execução, monitoramento, avaliação e fiscalização de projetos e ações. Isso pode ser vislumbrado na Constituição Federal de 1988, que criou mecanismos da chamada democracia participativa e que incentiva a participação dos cidadãos nas esferas do governo por meio das instâncias de controle social.

No entanto, os processos reivindicatórios e de luta manifestados com o auxílio da participação social são permeados pela correlação de forças entre a sociedade civil e o Estado. É importante destacar a interferência do Estado nas formas de participação social. Para subsidiar tal análise, utilizar-se-á a escala de participação popular apresentada por Souza (2006), a qual demonstra situações de não participação, graus de pseudoparticipação e graus de participação autêntica, conforme adaptação no quadro 1.
Quadro 1: Escala de participação popular

\begin{tabular}{|c|c|c|c|}
\hline & Grau & Categoria & Características \\
\hline \multirow{2}{*}{ 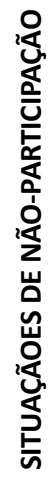 } & 1 & Coerção & $\begin{array}{l}\text { Notadamente vista em regimes } \\
\text { ditatoriais ou totalitários. No Brasil } \\
\text { pode ser vislumbrada em situações } \\
\text { que o Estado não se preocupa com } \\
\text { aparências, como a remoção de } \\
\text { favelas. }\end{array}$ \\
\hline & 2 & Manipulação & $\begin{array}{l}\text { Indução da população a aceitar uma } \\
\text { intervenção; ausência de diálogo; } \\
\text { existência de políticas públicas } \\
\text { compensatórias e intervenções } \\
\text { pontuais com o objetivo imediato } \\
\text { de ganhar eleições. }\end{array}$ \\
\hline \multirow{3}{*}{ 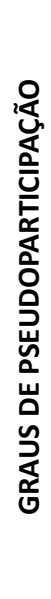 } & 3 & Informação & $\begin{array}{l}\text { Há uma disponibilização de } \\
\text { informações por parte do Estado } \\
\text { sobre as intervenções planejadas. } \\
\text { No entanto, isso dependerá de } \\
\text { aspectos culturais, políticos e do nível } \\
\text { de transparência do jogo político. }\end{array}$ \\
\hline & 4 & Consulta & $\begin{array}{l}\text { O Estado consulta a população, mas } \\
\text { isso não implica que as sugestões } \\
\text { serão incorporadas. }\end{array}$ \\
\hline & 5 & Cooptação & $\begin{array}{l}\text { Cooptação de sujeitos que exerçam } \\
\text { funções de liderança, representações } \\
\text { ou que sejam ativistas dentro da } \\
\text { sociedade. A participação, nesse } \\
\text { caso, não é deliberativa, apenas } \\
\text { de consulta. }\end{array}$ \\
\hline \multirow{3}{*}{ 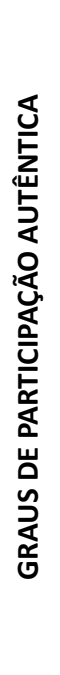 } & 6 & Parceria & $\begin{array}{l}\text { Há diálogo e significativa } \\
\text { transparência entre o Estado e a } \\
\text { sociedade civil organizada com } \\
\text { vistas à implementação de políticas } \\
\text { públicas ou a realização de uma } \\
\text { intervenção. }\end{array}$ \\
\hline & 7 & $\begin{array}{l}\text { Delegação } \\
\text { de poder }\end{array}$ & $\begin{array}{l}\text { O Estado renuncia significativas } \\
\text { atribuições, que Ihes eram exclusivas, } \\
\text { em benefício da sociedade civil. } \\
\text { É possível estabelecer a co-gestão } \\
\text { entre o Estado e a sociedade civil, } \\
\text { em algumas situações. }\end{array}$ \\
\hline & 8 & Autogestão & $\begin{array}{l}\text { A sociedade civil implementa } \\
\text { políticas e intervenções, incorpora } \\
\text { a autogestão com autonomia e } \\
\text { sem a necessidade da presença de } \\
\text { instâncias de poder. }\end{array}$ \\
\hline
\end{tabular}

Fonte: SOUZA (2006a).

Percebe-se que os graus de participação autêntica $(6,7$ e 8) remetem-se a uma sociedade civil organizada que participa da gestão pública na esfera das formulações, intervenções e deliberações de políticas públicas. Os graus referentes à pseudoparticipação $(3,4$ e 5$)$ revelam a ilusão que muitos sujeitos têm de que interferem na gestão pública, no entanto, na prática são marionetes no jogo político. As situações de não-participação são claramente compulsórias, não há interferência da sociedade civil no âmbito do planejamento e da gestão pública. 
Nessa experiência do MCMV é necessária a conexão de duas forças para garantir a dignidade dos sujeitos beneficiários, que são: a iniciativa do poder público em criar instrumentos e canais de participação social e as pressões populares com vistas ao direito de participar dos processos decisórios com a expressão das suas reais demandas e discussão sobre as possíveis soluções. Deve-se atentar para os conflitos políticos, interesses partidários e questões particulares da população que permeiam esse cenário.

Assim, é imprescindível que haja a integração e participação da população, entrelaçando meios que busquem a sustentabilidade e a inserção dos sujeitos no processo de planejamento participativo como formas de intervir na realidade que os cerca. Para que tais ações sejam efetivadas a população precisa: ser estimulada a formar uma mentalidade condizente com sua "[...] inserção no processo de desenvolvimento"; organizar seus esforços em prol de uma "[...] participação eficiente nos planos e programas de desenvolvimento"; além de ser incluída em "[...] programas de integração" subsidiados pelos "[...] esforços e recursos de setores públicos e privados" (WANDERLEY, 1998, p. 78).

Dessa forma, a partilha de responsabilidades, levandose em conta a participação do sujeito, assume um papel fundamental na formulação de políticas e/ou definição de prioridades das necessidades humanas e sociais de cada comunidade. O espaço participativo propicia a formação de um sujeito social, consciente e organizado, capaz de estabelecer suas prioridades, na defesa dos seus direitos.

A participação social não garante a escolha de caminhos certos e não elimina a existência de equívocos. No entanto, quanto maior for o nível de participação, maiores serão as possibilidades de transformação da realidade social e "[...] uma ampla participação pode contribuir para minimizar certas fontes de distorção (SOUZAb, 2006, p.333 grifos do autor)".

Isso requer um desenvolvimento gradativo por conta da quantidade de atores que estão envolvidos, sendo que cada um traz consigo uma noção da realidade e anseios particulares. É permeada por conflitos e lutas, mas só por meio dela é possível aos sujeitos, dentro de um Estado que assume o modo de produção capitalista e um modelo neoliberal, alcançarem a cidadania que implica na seguridade de direitos civis, políticos e sociais.

\section{PARTICIPAÇÃO SOCIAL NA POLÍTICA DE HABITAÇÃO EM FEIRA DE SANTANA}

A participação social requer um envolvimento coletivo com vistas a uma transformação social que represente as necessidades de um determinado grupo. Para que ocorram as mudanças desejadas no campo das políticas públicas, os sujeitos interessados devem tomar consciência das suas realidades, identificar demandas que anseiam superar e, coletivamente, reunirem-se em busca de soluções junto ao poder público (AMMANN, 2003). Em contrapartida, o poder público deve fornecer canais de participação para esses coletivos, conforme preconiza a Constituição de 1988.

De acordo com a Política Nacional de Participação Social (PNPS), Decreto no 8.243, de 23 de maio de 2014,

Art. 6อ São instâncias e mecanismos de participação social, sem prejuízo da criação e do reconhecimento de outras formas de diálogo entre administração pública federal e sociedade civil: I - conselho de políticas públicas; II - comissão de políticas públicas; III - conferência nacional; IV - ouvidoria pública federal; V - mesa de diálogo; VI - fórum interconselhos; VII - audiência pública; VIII - consulta pública; e IX - ambiente virtual de participação social (BRASIL, 2014).

Assim, com o intuito de verificar os instrumentos e canais que o poder público local disponibiliza para que haja participação social no âmbito da habitação em Feira de Santana, propõe-se refletir sobre a participação social prevista na legislação municipal que subsidia a política de habitação local. Como dito alhures, os documentos analisados foram: o PLHIS do município de Feira de Santana; a Lei no 3522/2015 que criou o Conselho da Cidade de Feira de Santana e o Relatório da 5 a Conferência da Cidade de Feira de Santana.

É válido salientar que o primeiro documento referente à legislação urbana de Feira de Santana foi o Plano de Desenvolvimento Local Integrado (PDLI), elaborado em 1968, que contou com a "participação popular inserida através de questionários [...] e entrevistas, principalmente com comerciantes [...], industriários e prestadores de serviços (médicos e outros)" (SANTO, 2012, p.124). Apesar de tratar-se de um período marcado pela Ditadura Militar, a equipe interdisciplinar que construiu esse Plano enfatizou a relevância da formação de lideranças para que essas elaborassem proposições em prol do desenvolvimento das comunidades (SANTO, 2012).

A mais recente proposta de Plano Diretor de Desenvolvimento Municipal (PDDM) é do ano de 2006, que é uma revisão da proposta de Plano Diretor de Desenvolvimento Urbano (PDDU) do ano de 2000. Todavia, ambas não foram instituídas, sendo que a de 2006 foi inviabilizada pelo Ministério Público, em decorrência da pequena participação popular (SANTO, 2012).

A Política de Habitação de Feira de Santana (PHFS) foi instituída no dia 15 de março de 2012 como Lei Complementar no 65. De acordo com os dados coletados na Secretaria Municipal de Habitação (SEHAB), a PHFS foi elaborada através de um trabalho participativo, desenvolvido nos anos de $2006 \mathrm{e}$ 2007, com o desenvolvimento de oficinas e audiências públicas.

Esse trabalho contou com a participação de representantes de associações de moradores, de entidades de ensino superior pública e privada, e grupos não formais. Esses sujeitos foram convidados com o apoio da Casa dos 
Conselhos, que possui uma lista com os nomes de lideranças comunitárias. Houve, também, a publicação de um edital de convocação, convites por meio de contato telefônico e e-mail.

Foram ofertadas oficinas de capacitação para instruir os participantes sobre a elaboração da política de habitação, em seguida, foram realizadas as audiências públicas, nas quais os presentes estabeleceram as necessidades locais no âmbito da habitação. Assim, os eixos de intervenção constituídos foram: requalificação habitacional e urbana; provisão de novas oportunidades habitacionais; implementação de Zonas Especiais de Interesse Social (ZEIS); e regularização fundiária (FEIRA DE SANTANA, 2012).

No entanto, com a criação do Fundo Nacional de Habitação de Interesse Social (FNHIS), o município de Feira de Santana teve que elaborar o PLHIS, tendo em vista que esse plano foi instituído como requisito indispensável para que o município acesse os recursos, sendo que é através dele que os municípios e estados materializam no âmbito local a Política Nacional de Habitação, condizente com as decisões decorrentes da participação da sociedade civil e também com os Planos Diretores (se houver) e os Planos Plurianuais (BRASIL, 2011).

Diante disso, a Lei Complementar no 65/2012 institui o PLHIS do município de Feira de Santana e informa no seu artigo 3ㅇ que houve ampla participação na construção, advinda, especialmente, do Orçamento Participativo. Além disso, nas diretrizes da Participação Popular do PLHIS há a institucionalização de canais de participação e controle social, dentre esses, cita-se a Conferência das Cidades a nível Municipal; o Conselho Municipal de Desenvolvimento Social, o Conselho Gestor do Fundo Municipal de Habitação de Interesse Social, e audiências e consultas públicas (FEIRA DE SANTANA, 2012).

No Relatório da 5o Conferência das Cidades, em nível municipal, estão dispostas algumas prioridades no âmbito da participação e do controle social, dentre essas cita-se duas que estão condizentes com a proposta de discussão ora apresentada: 1ㅇ- a implantação do Conselho da Cidade de Feira de Santana e 20- a imediata elaboração do PDDM participativo (FEIRA DE SANTANA, 2013).

No entanto, somente em abril de 2015 foi sancionada a Lei no 3522/2015 que criou o Conselho da Cidade de Feira de Santana e constitui parte integrante da gestão urbana no município (FEIRA DE SANTANA, 2015). Salienta-se que, em uma visita realizada a Casa dos Conselhos no mês de abril de 2016, constatou-se que o referido Conselho ainda não havia iniciado as suas atividades.

No mês de julho de 2016 ocorreu a 6ạ Conferência Municipal das Cidades e os membros do Conselho da Cidade de Feira de Santana, representantes da sociedade civil, foram eleitos. Todavia, em decorrência do período eleitoral, os conselheiros não tomaram posse e até o mês de janeiro de 2017 não foram identificadas atividades desse conselho.

Os conselhos municipais existentes e atuantes são: Assistência Social, Criança e Adolescente, Segurança Alimentar, Mulher, Idoso, Pessoa Portadora de Deficiência, Participação e Desenvolvimento de Comunidades Negras e Indígenas, Parlamento Juvenil, Desenvolvimento Econômico e dos Transportes. Assim, salienta-se a importância da atuação do Conselho das Cidades para discutir a política urbana e possibilitar que a sociedade civil participe das deliberações e implementações dessa política no município.

Em consulta ao site da Prefeitura, visualizou-se que, em janeiro de 2016, ocorreu uma reunião com os órgãos articuladores, executores e fiscalizadores do PMCMV em Feira de Santana, na qual estabeleceram a criação de um Disque-denúncia direcionado para a área de habitação e a criação do Conselho Municipal de Habitação. Entretanto, esses instrumentos ainda não foram instituídos.

Assim, quanto à existência de um canal de participação, direcionado para a política de habitação, instituído pelo poder público, identificou-se, através de uma visita técnica à Secretaria Municipal de Habitação, que as opções ofertadas para a sociedade civil são: direcionar-se as secretarias municipais, utilizarem o Sistema de Informação ao Cidadão (SIC) através do site da Prefeitura ou por contato telefônico ou recorrerem ao Conselho Municipal de Assistência Social.

Diante desse panorama, percebe-se algumas fragilidades na disponibilização de instrumentos e canais por parte do poder público de Feira de Santana para que haja participação social no âmbito da política de habitação. Para validar tal premissa, é importante citar que, com base na promulgação da Constituição, o município passou a ser reconhecido como "[...] ente autônomo da federação, transferindo-se para o âmbito local novas competências e recursos públicos capazes de fortalecer o controle social e a participação da sociedade civil nas decisões políticas" (BRAVO, 2012, p. 2).

Assim, o que se observou, através da presente análise documental, foi um PDDU do ano de 2006 que não foi instituído por insuficiência de participação popular; e um PLHIS que tem em suas diretrizes a institucionalização de instâncias de controle social, que na prática não atuam. Portanto, pode-se depreender que há fragilidades no processo de discussão, implementação, fiscalização e deliberação da política de habitação.

De acordo com informações disponibilizadas pela Secretaria Municipal de Planejamento e análise das atas, desde 2001 a participação da população no que concerne ao orçamento ocorre através de audiências públicas divididas por 5 regiões administrativas que delimitam o município, correspondentes à sede, e 8 aos distritos (Quadro 2) (Mapa 1).

As reuniões referentes à sede do município acontecem no auditório da Secretaria de Saúde e, conforme visto nos registros, a participação popular é pequena. Salienta-se a existência de atas negativas por não terem nenhum participante, e outras com apenas cinco pessoas. Talvez, em decorrência da localização, tendo em vista que facilitaria se 
Quadro 2: Regiões Administrativas da sede e dos distritos, Feira de Santana, Bahia

\begin{tabular}{|c|c|c|}
\hline & Região & Bairros integrantes \\
\hline \multirow{5}{*}{ 㞻 } & 1 & $\begin{array}{l}\text { Aeroporto; Mangabeira; Conceição I; Conceição II; } \\
\text { Rosário; Caseb; Bela Vista; Santo Antônio dos } \\
\text { Prazeres; Lagoa Grande; SIM; Parque Getúlio Vargas; } \\
\text { Capuchinhos; Santa Mônica; Lagoa Salgada; Subaé. }\end{array}$ \\
\hline & II & $\begin{array}{l}\text { 350 BI; Aviário; Irmã Dulce; Brasília; Eucalipto; } \\
\text { Jomafa; Tomba; Sítio Matias; Parque Panorama; } \\
\text { Feira VII; Luciano Barreto; Francisco Pinto; } \\
\text { Fraternidade; Limoeiro. }\end{array}$ \\
\hline & III & $\begin{array}{l}\text { Pedra do Descanso; Serraria Brasil; Chácara São } \\
\text { Cosme; Muchila I; Muchila II; Jardim Acácia; } \\
\text { Jussara; Mar da Tranquilidade; Olhos D'água; } \\
\text { Feira X; Viveiros; São João do Cazumbá; Centro } \\
\text { Industrial; Bem-te-vi. }\end{array}$ \\
\hline & IV & $\begin{array}{l}\text { Novo Horizonte; Campo Universitário; Asa Branca; } \\
\text { Campo Limpo; Feira Vl; Pampalona; Caraíbas; } \\
\text { George Américo; Campo do Gado Novo; Três } \\
\text { Riachos; Baraúna de Cima; Baraúna de Baixo; } \\
\text { Galileia; Jardim Cruzeiro; Alto do Cruzeiro; Nagé; } \\
\text { Cruzeiro; Tanque do Urubu; Barro Vermelho; } \\
\text { Calumbi; Morada do Sol; Feira IX; Feira IV; Parque } \\
\text { Manoel Matias; Tanque da Nação; Parque das } \\
\text { Acácias; Horto; DNER; Gabriela; Sobradinho; } \\
\text { Centro de Abastecimento; Monte Pascoal; J. J. } \\
\text { Lopes de Brito; Morada das Árvores; Minadouro; } \\
\text { Barroquinha; Nova Esperança; Três Riachos. }\end{array}$ \\
\hline & V & $\begin{array}{l}\text { Papagaio; Santa Quitéria; Cidade Universitária; } \\
\text { Parque Ipê; João Paulo II; Cidade Nova; Morada } \\
\text { do Bosque; Feira V; Milton Gomes; Iguatemi; } \\
\text { Queimadinha; São João; Prato Raso; Coronel José } \\
\text { Pinto; Estação Nova; Ponto Central. }\end{array}$ \\
\hline \multirow{8}{*}{ 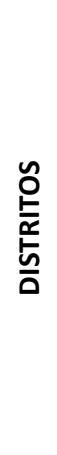 } & VI & Distrito Gov. João Durval Carneiro (Ipuaçu) \\
\hline & VII & Distrito de Bonfim de Feira \\
\hline & VII & Distrito de Maria Quitéria (São José) \\
\hline & IX & Distrito de Humildes \\
\hline & $x$ & Distrito de Tiquaruçu \\
\hline & $\mathrm{XI}$ & Distrito de Jaíba \\
\hline & XII & Distrito Jaguara \\
\hline & XIII & Distrito da Matinha \\
\hline
\end{tabular}

Fonte: Feira de Santana (2016).

as audiências acontecessem em locais próximos à população. $\mathrm{O}$ objetivo dessas audiências é levantar as prioridades e encaminhar às secretarias de competência para análise de viabilidade. Dessa forma, não há garantia de que as solicitações serão atendidas, pois trata-se de um processo de caráter consultivo (FEIRA DE SANTANA, 2015).

Na perspectiva do PMCMV em Feira de Santana, elucida-se o Trabalho Social que é desenvolvido com as famílias beneficiárias, através do Programa de Convivência Social e Cidadania (PSCS), e está sob a gestão do município. Esse trabalho conta com o apoio de uma equipe técnica multiprofissional que executa projetos sociais dentro dos empreendimentos do PMCMV. Salienta-se que o objetivo do Trabalho Social, de acordo com a Portaria 21 de 01 de Janeiro de 2014, é "[...] promover a participação social, a melhoria das condições de vida, a efetivação dos direitos sociais dos beneficiários e a sustentabilidade da intervenção" (BRASIL, 2014, p. 5).

Mesmo com a atuação da equipe técnica do PCSC dentro dos residenciais, o que se percebeu, através das visitas técnicas e do contato com os moradores, é que ainda há carência de informações sobre o tema participação social e, sobretudo, de espaços de participação instituídos pelo poder público. Deve-se levar em consideração que o projeto desenvolvido por essas equipes é direcionado para questões coletivas, como a organização da comunidade e a gestão condominial, bem como há o acompanhamento por família e, quando necessário, individualizado. Isso resulta em um trabalho que abarca inúmeras demandas e que é paulatino. No entanto, tem que cumprir um prazo definido, geralmente de um ano, que é estabelecido de acordo com o recurso federal disponibilizado.

Com isso, é possível analisar esse cenário com base na análise da escala de participação de Souza (2006a), pois percebe-se a similaridade da participação social no âmbito da política de habitação em Feira de Santana com o grau pseudoparticipação. Observa-se uma participação incipiente, de caráter informativo e consultivo, na qual o poder público realiza as audiências, institui leis e prioridades, no entanto, em contrapartida, não amplia a discussão e não desenvolve o que foi planejado na esfera do controle social para que assim possa ser possível realizar uma gestão democrática da política habitacional.

Há uma percepção que todo processo de participação social é paulatino, está sujeito a limitações e que não é possível alcançar desenvolvimento humano, vida sustentável e cidadania se os sujeitos não fizerem parte do processo de tomada de decisão das políticas públicas. Por isso é imprescindível "[...] solidificar os canais de comunicação e poder popular para que o Estado se coloque a serviço do povo", através da publicização do trabalho desenvolvido nas instâncias de controle social e do estabelecimento do diálogo em todas as esferas públicas (SOUZA, 2008, p. 221).

$\mathrm{O}$ indivíduo no contexto social que assume uma postura passiva e não se reconhece como ser político, capaz de decidir sobre os processos que dizem respeito a sua vida e a sociedade que ele faz parte, sujeita-se à subalternização, contribuindo para a dominação de uma classe sobre a outra.

\section{CONSIDERAÇÕES FINAIS}

A compreensão da categoria participação social como meio para o alcance de políticas públicas é um debate relevante, especialmente na área da habitação em Feira de Santana, uma vez que a cidade está em expansão. 

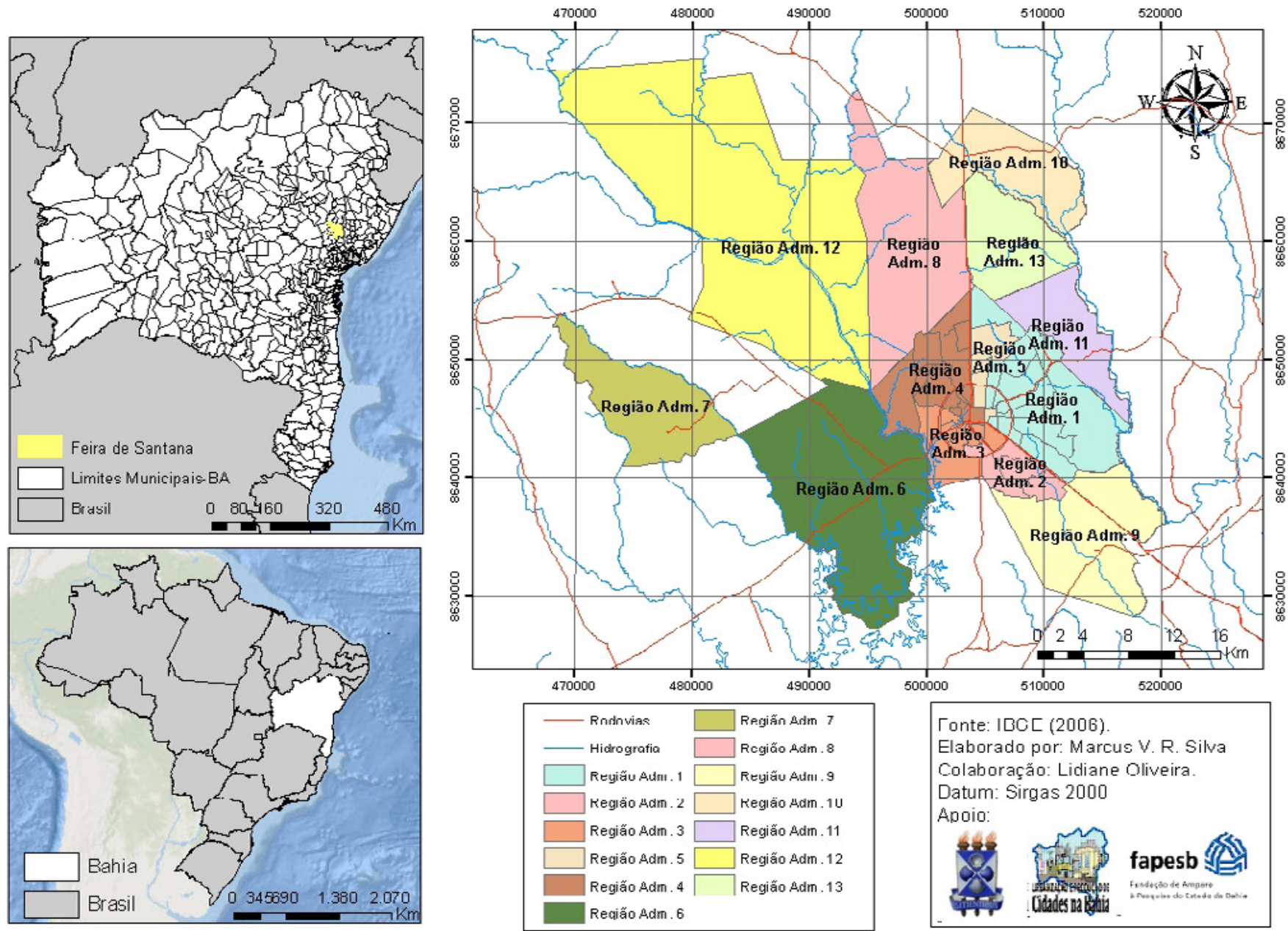

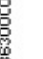

Mapa 1: Localização das Regiões Administrativas da sede e dos distritos, Feira de Santana, 2017

Foi importante adotar a escala de participação social de Souza (2006a), pois tal abordagem teórica estabeleceu um parâmetro para o reconhecimento de que em Feira de Santana a participação é incipiente, especialmente no âmbito da habitação. Observou-se, com base na pesquisa documental, nas visitas às Secretarias e à Casa dos Conselhos, que trata-se de uma pseudoparticipação, por possuir um caráter informativo, sobremodo, porque o poder público municipal não possui canais ativos de participação no âmbito da habitação, como, por exemplo, o Conselho Municipal das Cidades, que, apesar de criado, ainda não encontra-se atuante.

A ideia não é "culpabilizar" a sociedade civil ou o poder público pelo atual cenário da participação social em Feira de Santana, e até mesmo no Brasil. O que se pretende é demonstrar que as estratégias de aplicação dos mecanismos de participação social precisam ser revisadas e trabalhadas nas comunidades com um envolvimento maior. A gestão do município, além de sancionar leis e decretos, necessita instituir canais participativos que, de fato, desenvolvam o trabalho do controle social e também deve atentar-se para a divulgação desses canais e para a acessibilidade dos mesmos.

O que se sugere é a criação de instrumentos socioeducativos, realização de capacitações para a sociedade civil e para os servidores públicos, especialmente, para os que trabalham nos equipamentos da política de educação, assistência social e saúde. Tendo em vista que esses profissionais estão mais próximos das comunidades.

O envolvimento da sociedade civil é fundamental para que ocorra a gestão democrática. A inexistência de diálogo com o poder público compromete o desenvolvimento das políticas, uma vez que só ao ouvir a população é que se torna possível identificar as suas reais demandas.

\section{REFERÊNCIAS}

AMMANN, Safira Bezerra. Ideologia do desenvolvimento de comunidade no Brasil. 10ạ ed. São Paulo: Cortez, 2003.

BRASIL. Ministério das Cidades. Trabalho social e intervenções habitacionais: reflexões e aprendizados para o seminário internacional. Belo Horizonte: Ministério das Cidades, 2011. Disponível em: <http://gestaocompartilhada.pbh.gov.br/ sites/gestaocompartilhada.pbh.gov.br/files/biblioteca/ arquivos/trabalho_social_e_intervencoes_habitacionais. pdf>. Acesso: 14 dez. 2015.

BRASIL. Decreto 8.243, de 23 de maio de 2014. Institui a Política Nacional de Participação Social - PNPS e o Sistema Nacional de Participação Social - SNPS, e dá outras 
providências. Disponível em: <http://www.planalto.gov. br/ccivil_03/_Ato2011-2014/2014/Decreto/D8243.htm>. Acesso: 20 de jan. de 2017.

BRAVO, Maria Inês Souza. O trabalho do assistente social nas instâncias públicas de controle democrático. In: XX SEMINÁRIO LATINOAMERICANO DE ESCUELA DE TRABAJO SOCIAL. 2012, Argentina. Anais... Argentina: Universidad Nacional de La Plata, 2012, p. 1-10.

FEIRA DE SANTANA, Prefeitura da Cidade de; Lei Complementar № 65/2012, de 15 de março de 2012. Institui o Plano Habitacional de Interesse Social do Município de Feira de Santana - PLHIS e dá outras providências. Disponível em: <https://leismunicipais.com.br/a/ba/f/feira-de-santana/ lei-complementar/2012/7/65/lei-complementar-n-652012-institui-o-plano-habitacional-de-interesse-social-domunicipio-de-feira-de-santana-e-da-outras-providencias $>$. Acesso em: 15 de abril de 2016.

FEIRA DE SANTANA, Prefeitura da Cidade de; SEPLAN, Secretaria Municipal de Planejamento. Relatório da 5a Conferência Municipal das Cidades Feira de Santana. Feira de Santana: Prefeitura Municipal de Feira de Santana, 2013. Disponível em: <http://www.feiradesantana. ba.gov.br/seplan/conferencia/2013/Relatorio\%20 -\%20divulga\%C3\%A7\%C3\%A3०\%20-\%205\%C2\%AA\%20 Confer\%C3\%AAncia.pdf>. Acesso em: 15 de abril de 2016.

FEIRA DE SANTANA, Prefeitura da Cidade de; SEDESO, Secretaria Municipal de Desenvolvimento Social. Relatório de Acompanhamento do Trabalho Social do Programa de Convivência Social e Cidadania 2014. Feira de Santana: Prefeitura Municipal de Feira de Santana, 2014.

FEIRA DE SANTANA, Prefeitura da Cidade de; Lei № 3522/2015, de 02 de abril de 2015. Dispõe sobre a criação do Conselho da Cidade de Feira de Santana - CONCIDADE, e dá outras providências. Disponível em: <https://leismunicipais.com. br/a/ba/f/feira-de-santana/lei-ordinaria/2015/353/3522/ lei-ordinaria-n-3522-2015-dispoe-sobre-a-criacao-doconselho-da-cidade-de-feira-de-santana-concidade-e-daoutras-providencias?q=Lei\%20N\%BA\%203522\%2F2015>. Acesso em: 15 de abril de 2016.

GOHN, Maria da Glória. Conselho gestores e participação sociopolítica. São Paulo: Cortez, 2001.

SANTO, Sandra Medeiros. A expansão urbana, o Estado e as águas em Feira de Santana - Bahia (1940-2010). 275 f. Tese (Doutorado em Arquitetura e Urbanismo) - Faculdade de Arquitetura, Universidade Federal da Bahia, Salvador, 2012.

SILVA, Ronalda Barreto. Educação Comunitária: além do Estado e do mercado? A experiência da campanha nacional de escolas da comunidade (1985-1998). Campinas/SP: Autores Associados, 2003.

SOUZA, Celina. Políticas Públicas: uma revisão da literatura. Sociologias, Porto Alegre, ano 8, no 16, jul/dez 2006, p. 20-45.

SOUZA, Marcelo Lopes de. A prisão e a ágora: reflexões em torno da democratização do planejamento e da gestão das cidades. Rio de Janeiro: Bertrand Brasil, 2006a.

SOUZA, Marcelo Lopes de. Mudar a cidade: uma introdução crítica ao planejamento e à gestão urbanos. Rio de Janeiro: Editora Bertrand Brasil, 2006b.

SOUZA, Maria Luiza de. Desenvolvimento de comunidade e participação. São Paulo: Cortez, 2008.

WANDERLEY, Mariangela Belfiore. Metamorfoses do Desenvolvimento de Comunidade. 2 ed. São Paulo: Cortez, 1998. 